\title{
Internato Rural Médico na Atenção Primária à Saúde e controle da Hipertensão Arterial: um relato de experiência
}

Fernanda Mitre Cotta, Rodrigo Mitre Cotta, Isadora Brandão Pelucio, Luciana Saraiva da Silva, Filipe Souza Fernandes, Rosângela Minardi Mitre Cotta

\section{Resumo}

A hipertensão arterial (HA) é doença altamente prevalente, de elevado custo sociossanitário e impacto na morbimortalidade da população mundial. Uma das problemáticas da HA é o seu curso silencioso, o que implica no atraso do início do tratamento e nas baixas taxas de controle da doença, entretanto, 60 a $80 \%$ dos casos podem ser tratados em nível de Atenção Primária à Saúde (APS), pois são de fácil diagnóstico, não requerem tecnologia sofisticada, podendo controlados com medicamentos de baixo custo e mudanças de estilo de vida. No Brasil, a Estratégia de Saúde da Família (ESF) constitui-se em lócus prioritário para controle e tratamento da HA no âmbito da APS. Apresentar o relato de experiência de acadêmicos de medicina no controle da HA em estágio de Internato rural na ESF. O estudo foi desenvolvido no município de Catas Altas da Noruega, Minas Gerais. A investigação baseou-se em 3 etapas complementares: estudo observacional a fim de conhecer o território e as necessidades locais, palestras dialogadas para os portadores de HA e coleta dos dados em consultas individualizadas. Participaram do estudo 15 portadores de HA, sendo a maioria mulheres; idosos, com média de idade de 63 anos; não tabagistas; não etilistas e com prevalência de $60 \%$ de sobrepeso e média de índice de massa corporal (IMC) de $27,1 \mathrm{~kg} / \mathrm{m} 2$. Encontraram-se falhas no uso de medicamentos anti-hipertensivos, devido à falta de acompanhamento periódico pelos profissionais. Cita-se, por exemplo, que os pacientes em uso de Metildopa (simpaticolítico de ação central), medicamento principalmente indicado para doentes renais crônicos e gestantes, não se encontravam em nenhuma destas duas condições; pacientes em uso de Captopril (inibidores da enzima conversora da angiotensina - IECA), que tomavam 1 comprido ao dia, sendo que deveria ser utilizado no mínimo 1 comprimido a cada 12 horas, devido a sua meia vida curta. Referente às atividades em grupo, a equipe médica e de enfermagem, realizou palestras dialogadas e dinâmicas com os portadores de HA, versando sobre orientações relativas aos hábitos de vida saudáveis e à importância do uso de medicamentos na dosagem correta. Estas atividades propiciaram a formação de vínculos entre os profissionais, pacientes e familiares, além da redução dos valores de PA e consequente melhoria da qualidade de vida da população em estudo. Após a realização de intervenções educativas $86,7 \%$ tiveram redução nos valores da pressão. Os achados apontam para a importância de um acompanhamento sistemático, contínuo e longitudinal dos portadores de HA, e a importância do internato médico em serviços de APS, visando a capacitação dos futuros médicos e a experiência de trabalho interdisciplinar no âmbito da ESF. O estudo demonstra ainda a importância da APS, visto que esta é a porta de entrada dos indivíduos nos serviços de saúde, e o lugar onde o controle e a prevenção de complicações devem ser estabelecidos. Há que se salientar ainda, o papel primordial da ESF em municípios de pequeno porte, já que esta constitui a única possibilidade de cuidado terapêutico em nível local.

Descritores: Internato rural; Hipertensão arterial; Atenção primaria a saúde. 